\title{
Zucchelli's Modified Coronally Advanced Flap Technique for the Treatment of Multiple Recession Defects - A Case Report
}

\author{
Sneha Walkar', P.S Rakhewar ${ }^{2}$, Lisa Chacko ${ }^{3}$, Saihas Pawar ${ }^{4}$
}

\begin{abstract}
When multiple recession defects affecting adjacent teeth in aesthetic areas of the mouth are present, patient related considerations suggest the selection of the surgical techniques that allow all gingival defects to be simultaneously corrected with the soft tissue close to the defects themselves. The present case report highlights the effectiveness of Zucchelli's modified coronally advanced flap with envelope technique for the treatment of multiple recession defects in patients with aesthetics demands.
\end{abstract}

Keywords: aesthetics; gingival recession; root coverage; surgery

\section{Introduction}

Gingival recession can be defined as the location of gingival margin apical to cemento-enamel junction .${ }^{[1]}$ Aesthetics is the primary indication for root coverage surgical procedures. ${ }^{[2]}$ The international literature has thoroughly documented that gingival recession can be successfully treated by several surgical approaches, ${ }^{[3,4]}$ provided that the biologic conditions for accomplishing root coverage are satisfied: no loss of height of interdental soft and hard tissues. ${ }^{[5]}$ In patients with an aesthetic request, the most important outcome is the percentage of complete root coverage, i.e, the proportion of treated defects with the soft tissue margin at the level of or coronal to cemento-enamel junction (CEJ). ${ }^{[4,5,6,7]}$

The coronally advanced flap is the first choice in patients with high aesthetic expections, when there is adequate keratinized tissue apical to the root exposure. With this approach, the soft tissue used to cover the root exposure is similar in color, texture, and thickness to that originally present at the buccal aspect of the tooth with the recession defect; thus, the aesthetic result is more satisfactory.

Multiple gingival recessions, affecting aesthetic areas of the mouth, were successfully treated with an envelope type of coronally advanced flap. ${ }^{[7]}$ The presumed advantage of the envelope type of flap is the lack of vertical releasing incisions, which could damage the lateral blood supply to the flap and might result in unaesthetic visible white scars(keloids). ${ }^{[8]}$ This case report describes Zucchelli's modified coronally advanced flap with envelope technique for the treatment of multiple recession defects in patients with aesthetics demands.

\section{Case Report}

A 35 year old female patient reported to the department of periodontology, SMBT dental college and research center, with a chief complaint of poor esthetics due to receded gums in the upper left front region of the jaw with no relevant medical history. On clinical examination, Miller's class I recession was evident with 23 and 24 [Fig. 1A], with recession depth of $3 \mathrm{~mm}$ and $2 \mathrm{~mm}$ and width of $4 \mathrm{~mm}$ and $3 \mathrm{~mm}$ respectively [Fig. 1B,1C]. The periodontium was healthy with no signs of inflammation. At first visit after recording case history of the patient and routine investigations, thorough scaling and root planing was performed. After 1 month root coverage with Zucchelli'scoronally advanced flap was planned and informed consent was obtained from the patient.

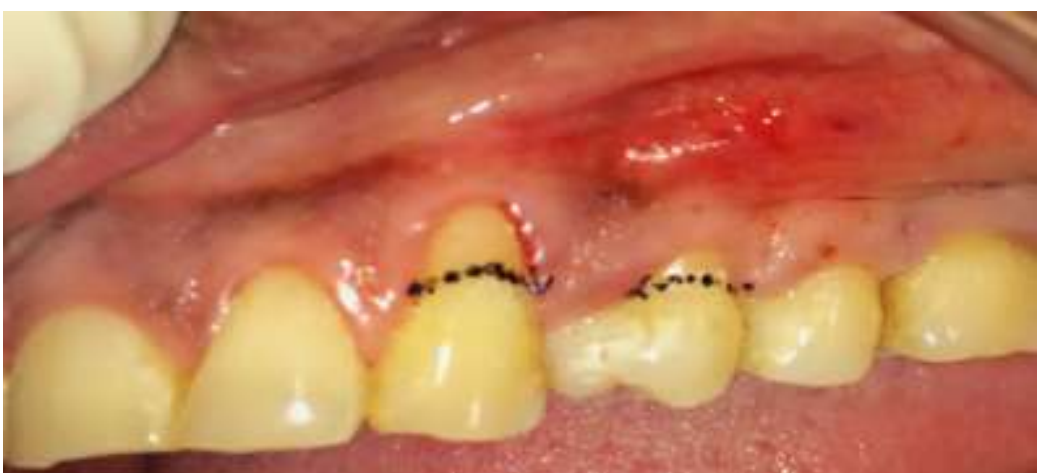

Fig.1A- Pre-operative presentation 


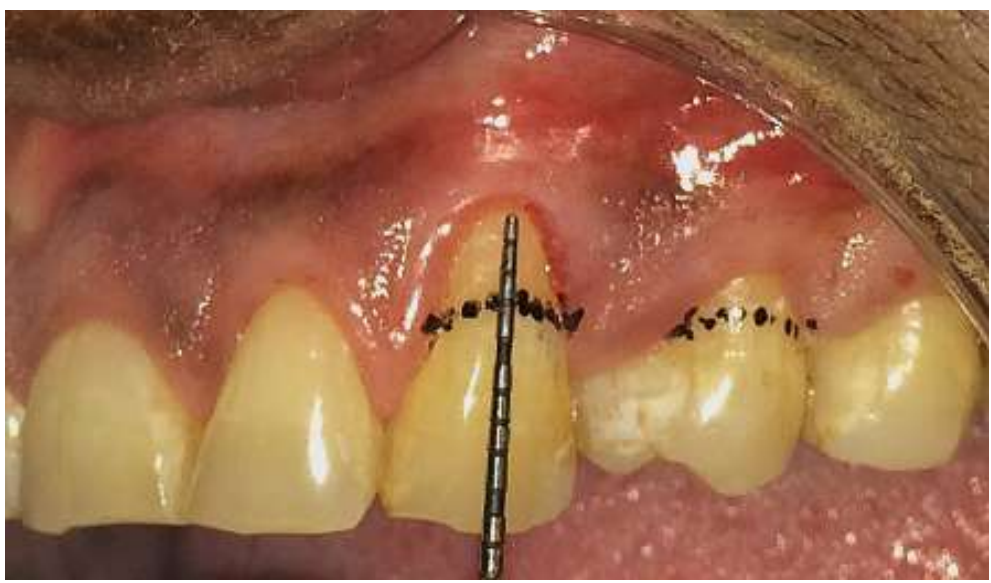

Fig 1B. depth-3mm, width-4mm

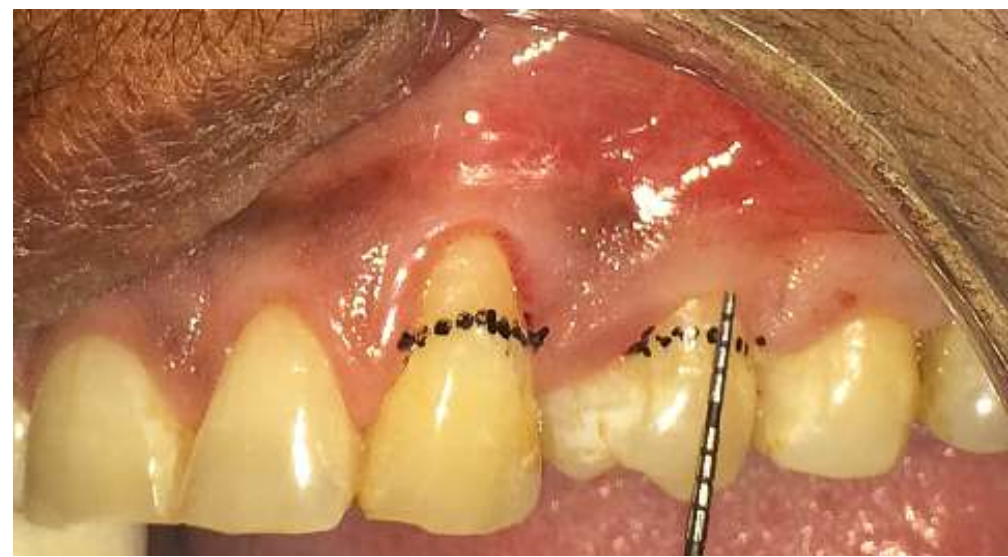

Fig 1C. depth-2mm, width-3mm

\section{Surgical Procedure}

Zucchelli's technique: Modification of coronally advanced flap for multiple teeth recession coverage. ${ }^{[9]}$ Clinical features of Zucchelli's technique are the absence of vertical releasing incisions, a variable thickness, combining areas of split and full thickness and the coronal repositioning of the flap. Another characteristic feature is the submarginal oblique incisions in the interdental area. Incisions are given obliquely connecting the CEJ of one tooth to the gingival margin of the adjacent tooth. ${ }^{[10]}$ [Fig. 2].

Disinfection of the surgical site was done with $2 \%$ betadine. The procedure was carried out under local anesthesia (lignocaine HCL with 2\% epinephrine 1: 200,000. A horizontal incision was made with a scalpel to design an envelope flap. The incision was extended to include one tooth on each side of the teeth to be treated in order to facilitate the planned coronal repositioning of the flap tissue over the exposed root surfaces.

The horizontal incision of the envelope flap consisted of oblique submarginal incisions in the interdental areas, incisions which continued as intrasulcular incisions at the recession defects [Fig. 3]. The envelope was raised with a split-full-split approach in the coronal-apical direction: the oblique interdental incisions were carried out keeping the blade parallel to the long axis of the teeth in order to dissect in a splitthickness manner the surgical papilla. Gingival tissue apical to the exposure was raised in a full-thickness manner to provide that portion of the flap critical for root coverage with more thickness. Finally the most apical portion of the flap was elevated in a split-thickness manner to facilitate the coronal displacement of the flap [Fig. 4].

The root surfaces were mechanically treated with the use of curettes. Exposed root surfaces in areas of anatomic bone dehiscence were not instrumented to avoid damaging any connective tissue fibers still inserted in the root cementum. The remaining tissue of the anatomic interdental papillae was de-epithelized to create connective tissue beds to which the surgical papilla were sutured [Fig. 5]. While advancing the flap coronally, surgical papillae were rotated towards the ends of the flap and were displaced on the prepared connective tissue beds of the anatomical papillae. The flap was secured in place with interrupted sutures [Fig. 6]. This ensured precise adaptation of the flap. The surgical site was then covered with periodontal dressing (coe-pak) 


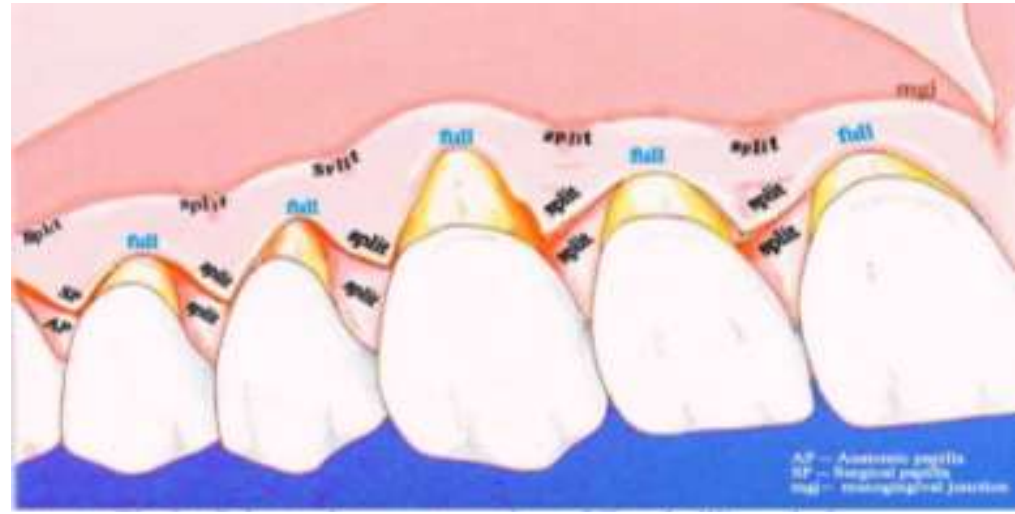

Fig 2. Schematic representation of zucchelli's technique

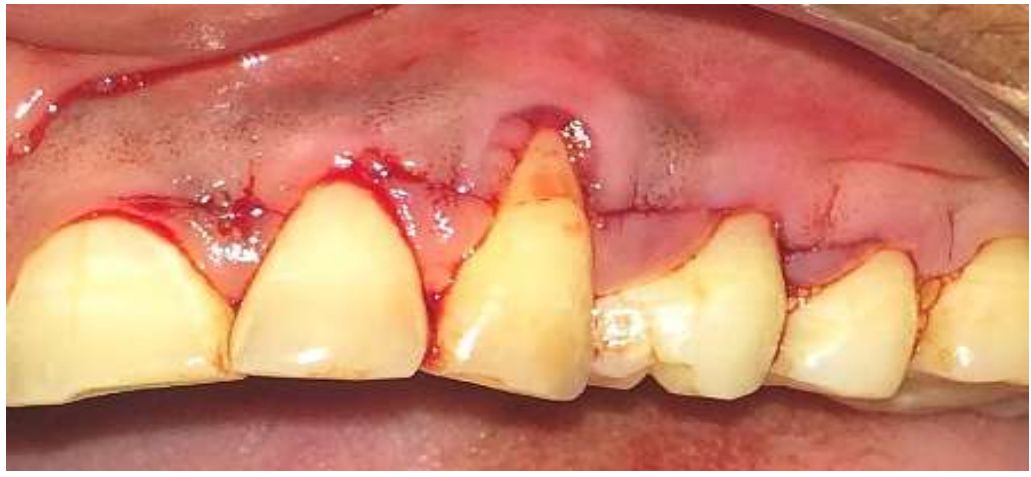

Fig 3.Submarginal oblique incisions

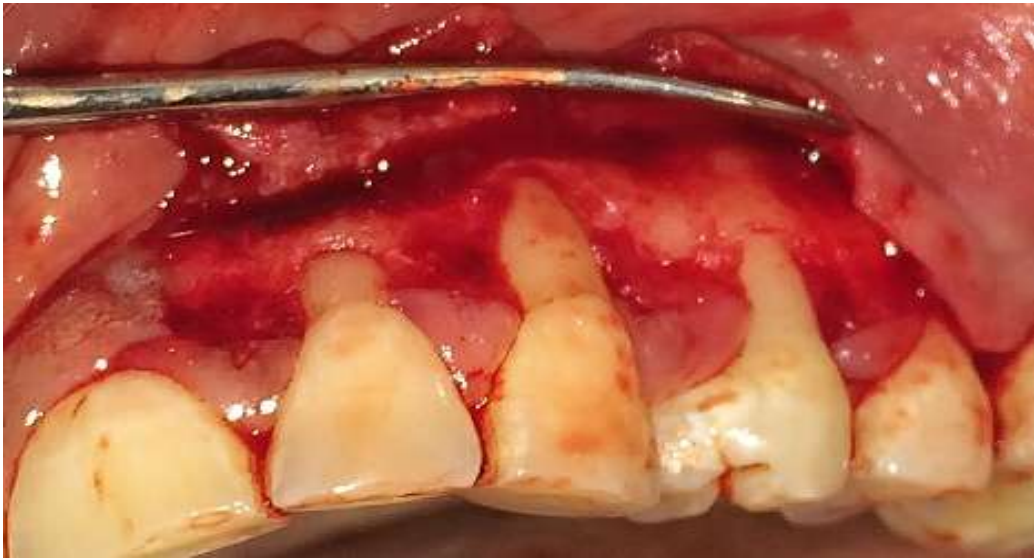

Fig 4. Split-full-split thickness flap

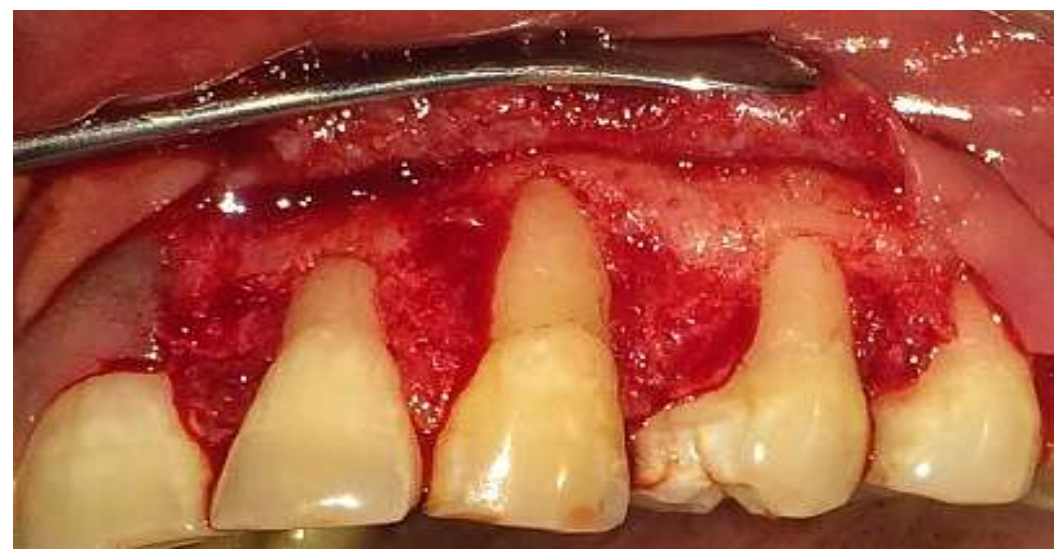

Fig 5. Deepithelization of anatomic papillae 


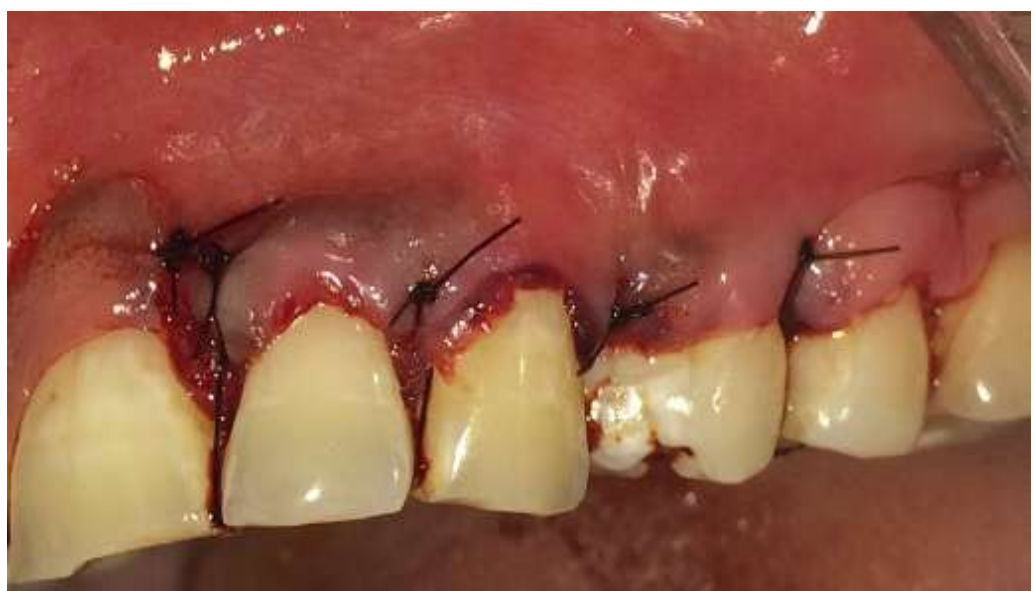

Fig 6. Coronal mobilization and suturing

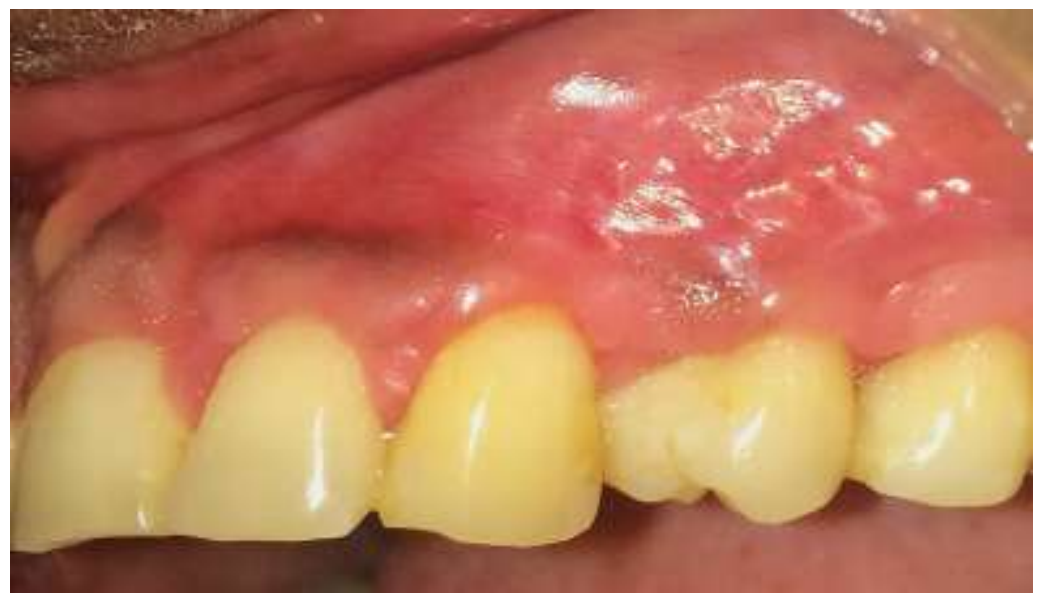

Fig 7. 3 monthspost operative

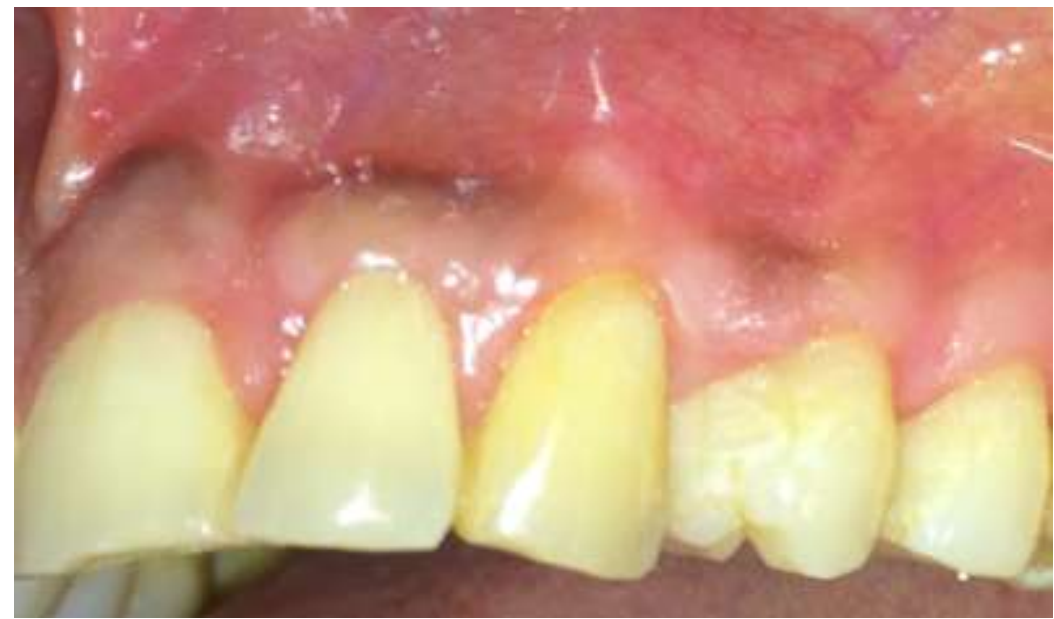

Fig 8. 6 monthspost operative

\section{Post Operative Care}

The Patient was instructed not to remove the pack or disturb the surgical site in any way till the sutures were removed and was also instructed not to brush the teeth in the treated area but to rinse the mouth with chlorhexidine solution $(0.12 \%)$ twice daily for 1 minute. Patient was advised to take antibiotics and analgesic ( amoxicillin $500 \mathrm{mg}$ tds and aceclofenac $100 \mathrm{mg}+$ paracetamol $500 \mathrm{mg}$ tds ) for 3 days postoperatively. Two weeks post operatively the periodontal dressing and the sutures were removed. Healing was satisfactory and adequate root coverage was obtained. Recall after 3 and 6 months revealed stable results with excellent tissue contour, color match and increase of keratinized tissue [Fig. 7,8]. 


\section{Discussion}

Treatment of gingival recessions has become an important therapeutic issue due to the increasing number of cosmetic requests from patients. Patients aesthetic demands, due to the exposure, during smiling or function, of portions of the root surface are the main indication for root coverage surgical procedures. Very often, the area with the most coronal millimetre(s) of root exposure is the only visible part of the recession when smiling; therefore, the presence after therapy even of a shallow recession may be an aesthetic concern for the patient. Thus, complete root coverage upto the CEJ is the goal to be achieved when the patient complains about aesthetic appearance of teeth. Furthermore, even if complete root coverage is surgically accomplished, the result may not be completely satisfactory in the case of excessive thickness or poor blending of the area. ${ }^{[8]}$

Another factor to be considered is that gingival recession is very seldom localized to a single tooth. More frequently, gingival recession affect groups of adjacent teeth. In order to minimize the number of surgeries and to optimize the aesthetic result, all the contiguous recessions should be treated at the same time. The coronally advanced flap procedure has been demonstrated to be a reliable and predictable treatment modality for obtaining root coverage in isolated types of gingival recessions. ${ }^{[9,11,12]}$ In the present case report, a new approach to the coronally advanced flap was used to treat multiple recession defects affecting adjacent teeth in patients with aesthetic demands. Some clinical and biological advantages are derived from the use of this new surgical approach. In the envelope type of flap, vertical releasing incisions are avoided so as not to damage the blood supply to the flap; this is of paramount importance in root coverage procedures where the stability of the root coverage procedures where the stabiltity of the surgical margin is critical to the success of the surgery. Furthermore, vertical releasing incisions often result (after healing) in unaesthetic, visible white scars which can be more unsatisfactory for the patient than the root exposure itself. Other advantages are derived from the splitfull-split flap elevation. In fact, more thickness (and thus better opportunity to achieve root coverage) is provided for that portion of the flap residing over the previously exposed root exposures; it facilitates the coronal displacement of the flap; and it guarantees anchorage and blood supply to the surgical papilla in the interproximal areas between the root exposures. ${ }^{[8]}$

The present case report demonstrated that the proposed modification of the coronally advanced flap is an effective treatment modality for the management of multiple recession defects affecting adjacent teeth in aesthetic regions of the mouth both in terms of root coverage and increase in keratinized tissue.

\section{Conclusion}

The results of the present case demonstrated that this new approach to the coronally advanced flap technique was very effective for the treatment of multiple gingival recessions in patients with esthetics demands both in terms of root coverage and increase in keratinized tissue.

\section{References}

[1]. Glossary of periodontal terms-2001 $4^{\text {th }}$ edition

[2]. American academy of periodontology. Consensus report on mucogingival therapy. Proceedings of the world workshop in periodontics. Ann periodontal 1996;1:702-706.

[3]. Wennstrom JL. Proceedings of the $1^{\text {st }}$ European workshop on periodontology. Mucogingival surgery. In: Lang NP,Karring T, eds. Berlin: Quintessence publishing; 1994: 193-209

[4]. Wennstrom JL. Proceedings of the 1996 world work shop in periodontics. Ann periodontal 1996; 1:667-701.

[5]. Miller PD. A classification of marginal tissue recession. Int J Periodontics Restorative Dent 1985; 5:8-13.

[6]. De sanctis M, Zucchelli G. coronally advanced flap: a modified surgical approach for isolated recession-type defects: three year results.J ClinPeriodontol2007;34:262-268.

[7]. Zucchelli G, De Sanctis M. Treatment of multiple recession type defects in patients with aesthetic demands. J Periodontol2000;71:1506-1514.

[8]. G Zucchelli, M. Mele. Coronally advanced flap with and without vertical releasing incisions for the treatment of multiple gingival recessions: a comparative controlled randomized clinical trial. J Periodontol 2009;1083-1094.

[9]. Allen EP, Miller PD. Coronal positioning of existing gingiva: short term results in the treatment of shallow marginal tissue recession. J Periodontol1989;60:316-319.

[10]. Baldini. N, Zucchelli. G, Sanctis M. A novel surgical technique for soft tissue management in aesthetic areas of the mouth at implacement - A case report. Journal de parodontologic\&d'Implantologic 2010;29(4): 1-8.

[11]. Wennstrom JL, Z uccheli G. Increased gingival dimentations. A significant factor for successful outcome of root coverage procedures? J ClinPeriodontol1996;23:770-777.

[12]. Tenenbaum H, Klewansky P, Roth JJ. Clinical evaluation of gingival recession treated bycoronally repositioned flap technique. J Periodontol1980;51:686-690. 